Revista Destaques Acadêmicos, Lajeado, v. 13, n. 2, 2021. ISSN 2176-3070

DOI: http://dx.doi.org/10.22410/issn.2176-3070.v13i2a2021.2797

http://www.univates.br/revistas

\title{
POVOS INDÍGENAS E A UNIVERSIDADE: REVISÃO INTEGRATIVA
}

\author{
Letícia Cunha Franco ${ }^{1}$, Matheus Henrique Rodrigues da Silva ${ }^{2}$, \\ Thais Dias Venâncio Ferreira ${ }^{3}$
}

\begin{abstract}
Resumo: Objetivo: Evidenciar a produção de conhecimento acerca de povos indígenas e a universidade. Método: revisão integrativa da literatura nacional em quatro bases de dados, com os descritores universidade, indígenas e ações afirmativas. Resultados: foram identificados 544 estudos e selecionados 11. O maior número de publicações ocorreu no ano 2017 (36,3\%),e por revistas na temática de psicologia e educação (90,9\%), e todos os estudos com abordagem qualitativa. As categorias temáticas de destaque foram: interculturalidade e formação acadêmica, e Ações afirmativas, em ambas, 5 (cinco) (45,4\%) estudos. Conclusão: A produção de conhecimento quanto a vivência universitária dos povos indígenas ainda é incipiente, diante da repercussão das políticas afirmativas nas transformações educacionais, socioeconômicas, e biopsicossociais para o indivíduo, família e/ou comunidades. Doravante, espera-se que esta revisão sensibilize e mobilize, para o aumento das discussões e ações, no âmbito da qualidade da permanência do estudante indígena na universidade.
\end{abstract}

Palavras-chave: Universidade. Indígenas. Ações Afirmativas.

\section{INTRODUÇÃO}

A população indígena brasileira é composta por 230 diferentes povos e 817.963 pessoas, das quais 502.783 vivem na zona rural e 315.180 nas zonas urbanas, mas com distribuição em todo o país. Considerando, ainda, que há 74 línguas faladas e 17,5\% da população indígena não fala a língua portuguesa (IBGE, 2010).

Fatores como a migração e transculturalidade, repercutiram nos hábitos e estilo de vida, potencializando complexa transformação social e, determinando

1 Professora Doutora em Enfermagem atuante no Departamento do curso de Medicina da Universidade Federal de Catalão, Catalão-GO.

2 Discente do curso de enfermagem da Universidade Federal de Catalão, Catalão-GO.

3 Licenciada em Letra pela Universidade Federal de Catalão, Catalão-GO. 
novos caminhos para sobrevivência, qualidade de vida e de perpetuação das etnias, visto que, a urbanização e/ou aculturação também é acompanhada de problemas, como: conflitos por território e ambiente; exploração sexual e por subempregos; uso e abuso de drogas lícitas e ilícitas; mendicância; e alta migração.

A migração por melhor qualidade de vida, refletiu no interesse pelo ingresso na Educação Superior, que foi melhor oportunizado a partir da Lei de Cotas para o ensino público federal de nível médio-técnico e superior (BRASIL, 2012), uma política pública de Ação Afirmativa. Essa medida legal e obrigatória, determina que as Universidades, Institutos e Centros Federais, reservem 50\% das suas vagas para estudantes oriundos de escola pública. Dentre elas, um percentual destinado a estudantes negros e indígenas.

No Brasil, a Universidade Estadual do Rio de Janeiro foi a precursora nesse processo, implementando em 2003 o primeiro Programa de Cotas brasileiro. Por conseguinte, inaugura-se no país um período de grandes especulações acerca das consequências desses programas, ao

mesmo tempo em que também outras universidades, foram incorporando o sistema de cotas ao processo seletivo. Atualmente, 48 universidades adotam a Lei de Cotas e em menos de sete anos, a quantidade de pessoas indígenas matriculadas nas universidades cresceu mais de cinco vezes. O aumento na procura por formação acadêmica entre os povos indígenas, devese a necessidade de formar profissionais qualificados e inseridos em contextos políticos e socioculturais, e que ainda colaborem com a luta pela conquista da autonomia e da sustentabilidade de seu povo (BRASIL, 2018). O Censo da Educação Superior (BRASIL, 2017) mostra que o número de pessoas indígenas matriculadas em instituições públicas e privadas cresceu 52,5\% de 2015 para 2016, passando de 32.147 para 49.026 .

A maior oportunização de ingresso da pessoa indígena à Universidade e por meio de Ações Afirmativas, remete à reflexões acerca do processo de adaptação e permanência no cenário universitário. Por isso, nos instiga desvelar a produção de saberes quanto à Educação Superior, as Ações Afirmativas e os povos indígenas, mediante a pergunta de pesquisa: "Qual o perfil da produção científica acerca de povos indígenas e a universidade"?

Deste modo, o presente estudo buscou evidenciar o perfil da produção de conhecimento no país acerca de povos indígenas e a universidade.

\section{MÉTODO}

Trata-se revisão integrativa da literatura, o que possibilita analisar a produção científica existente, fornecendo ampla compreensão de determinado objeto de estudo. A abrangência à diversos temas e/ou desenhos de estudo contribui para a prática baseada em evidência científica (WHITTEMORE; KNAFL, 2005). 
Para a elaboração deste estudo foram seguidas as etapas (WHITTEMORE; KNAFL, 2005): formulação do problema e pergunta de pesquisa, em conjunto com a elaboração e aprovação do protocolo de revisão; coleta, análise, interpretação, e organização dos dados em categorias; e apresentação dos resultados e conclusões. Considerando, ainda, os critérios de elegibilidade (texto completo; idioma (português); ano de publicação (até 10 anos); tipo de estudo (artigo); responder ao tema de pesquisa elou ter pertinência com o objetivo do estudo; e de inelegibilidade (duplicidade).

E por meio da elaboração de protocolo de busca (WHITTEMORE; KNAFL, 2005), foi estabelecida a estratégia de coleta dados e de análise dos resultados encontrados. O que permitiu o desenvolvido do estudo de revisão integrativa de literatura, para busca de informações de forma sistematizada e posterior análise dos contextos/resultados/reflexões acerca da temática.

A coleta de dados foi realizada em outubro de 2020 nas bases de dados: Literatura Latino-Americano e do Caribe em Ciências da Saúde (LILACS), Medical Literature Analysis and Retrieval System Online (MEDLINE), Scientific Electronic Library Online (SciELO) e Bases de Dados de Enfermagem (BDENF), utilizando-se os descritores e/ou palavras-chave: Universidade, Indígenas e Ações Afirmativas. E por meio da combinação dos descritores foi realizada a sistematização da busca (Fluxograma 1):

$1^{a}$ etapa: Pesquisa por Título, Resumo e Assunto, com aplicação dos critérios de elegibilidade.

$2^{a}$ etapa: Leitura e análise dos artigos selecionados para ratificação ou exclusão.

Fluxograma 1 - Artigos incluídos no estudo. Catalão/GO, Brasil, 2020.

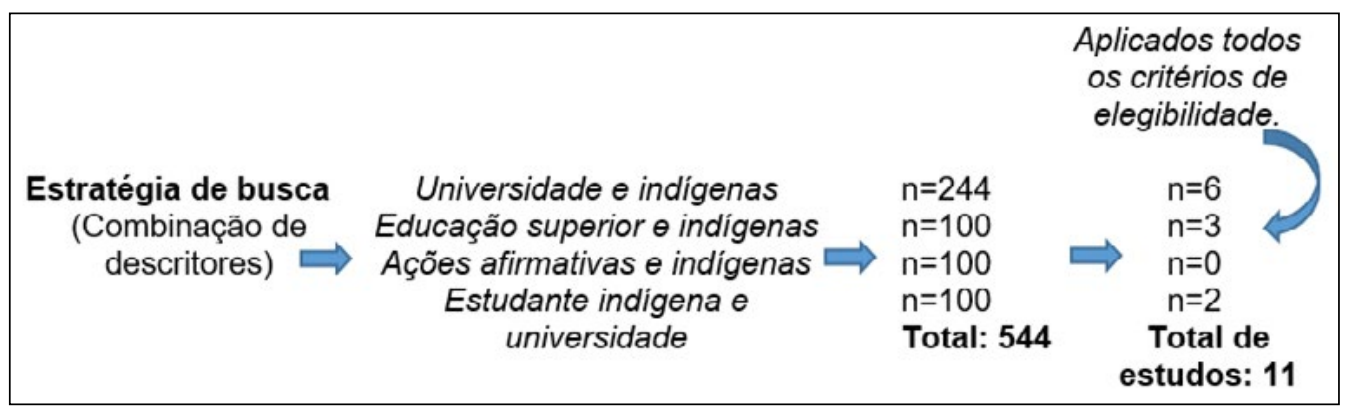

Fonte: Dados da pesquisa, 2020.

A análise e interpretação dos dados foram realizadas por meio de visualização em uma tabela no Microsoft Office Word, que foi organizada em linhas e colunas, com síntese dos estudos: título; ano de publicação; periódico; base de dados; tipo de estudo; reflexões/conclusões dos autores. 


\section{RESULTADOS E DISCUSSÃO}

A partir da coleta de dados localizaram-se 544 estudos, que foram submetidos à primeira etapa de avaliação por meio da aplicação dos critérios de elegibilidade e inelegibilidade previamente definidos. E posteriormente, realizada a leitura e análise dos artigos selecionados para identificar aqueles que respondiam à questão de pesquisa e/ou tinham pertinência com o objetivo do estudo, totalizando no final da segunda etapa 11 estudos, todos encontrados na base de dados LILACS (Quadro 1).

Quadro 1. Caracterização dos estudos selecionados. Catalão/GO, Brasil, 2020.

\begin{tabular}{|c|c|c|c|c|}
\hline \multicolumn{2}{|r|}{ Título } & $\begin{array}{l}\text { Ano/ } \\
\text { Periódico/ } \\
\text { Base de } \\
\text { dados }\end{array}$ & Tipo de Estudo & Reflexões/conclusões \\
\hline \multicolumn{5}{|c|}{ DESCRITOR: UNIVERSIDADE E INDÍGENAS } \\
\hline 1. & $\begin{array}{l}\text { Colonialidade, invisibilização e } \\
\text { potencialidades: } \\
\text { Experiências de indígenas no } \\
\text { ensino superior }\end{array}$ & $\begin{array}{l}\text { 2019/ } \\
\text { Psicologia } \\
\text { Polítical } \\
\text { LILACS }\end{array}$ & $\begin{array}{l}\text { Qualitativo/ } \\
\text { Relato de } \\
\text { experiência }\end{array}$ & $\begin{array}{l}\text { Interculturalidade e formação } \\
\text { acadêmica } \\
\text { Problematização das experiências } \\
\text { de indígenas } \\
\text { No contexto universitário, } \\
\text { tomando a noção de colonialidade } \\
\text { como articuladora da análise. }\end{array}$ \\
\hline 2. & $\begin{array}{l}\text { Estudantes de } \\
\text { cotistas e } \\
\text { odontológico }\end{array}$ & $\begin{array}{c}\text { 2019/ABENO/ } \\
\text { LILACS }\end{array}$ & $\begin{array}{l}\text { Qualitativo/ } \\
\text { Relato de } \\
\text { experiência }\end{array}$ & $\begin{array}{l}\text { Ações afirmativas } \\
\text { A aquisiça do instrumental } \\
\text { exigido no curso de Odontologia, } \\
\text { representa grande dificuldade para } \\
\text { a permanência da maioria dos } \\
\text { estudantes indígenas. }\end{array}$ \\
\hline 3. & $\begin{array}{l}\text { Temporalidade e Corpo numa } \\
\text { Proposta de Formaça do } \\
\text { Psicólogo para o Trabalho com } \\
\text { Povos Indígenas }\end{array}$ & $\begin{array}{l}\text { 2019/Psicol. } \\
\text { ciênc.prof./ } \\
\text { LILACS }\end{array}$ & $\begin{array}{l}\text { Qualitativo/ } \\
\text { Relato de } \\
\text { experiência }\end{array}$ & $\begin{array}{l}\text { Interculturalidade e formação } \\
\text { acadêmica } \\
\text { Processo de formação de psicólogos } \\
\text { para o diálogo com diversas } \\
\text { culturas. }\end{array}$ \\
\hline 4. & $\begin{array}{l}\text { Estudantes indígenas na } \\
\text { Universidade: uma sessão de } \\
\text { grupo operativo }\end{array}$ & $\begin{array}{l}\text { 2018/Vinculo. } \\
\text { /LILACS }\end{array}$ & $\begin{array}{l}\text { Qualitativo/ } \\
\text { Grupo operativo }\end{array}$ & $\begin{array}{l}\text { Ações afirmativas } \\
\text { Identificação dos discursos } \\
\text { de alunos indígenas de uma } \\
\text { Universidade pública }\end{array}$ \\
\hline 5. & $\begin{array}{l}\text { A construção do projeto de vida e } \\
\text { carreira em estudantes indígenas: } \\
\text { um estudo exploratório }\end{array}$ & $\begin{array}{l}\text { 2017/Psicol. } \\
\text { soc./LILACS }\end{array}$ & $\begin{array}{c}\text { Qualitativo/ } \\
\text { Análise temática }\end{array}$ & $\begin{array}{l}\text { Interculturalidade e formação } \\
\text { acadêmica } \\
\text { Projetos de vida e carreira dos } \\
\text { estudantes indígenas em uma } \\
\text { universidade pública. }\end{array}$ \\
\hline 6. & $\begin{array}{l}\text { Transições e reconfigurações } \\
\text { do self de jovens indiggenas na } \\
\text { experiência universitária }\end{array}$ & $\begin{array}{l}\text { 2017/Psicol. } \\
\text { esc. educ./ } \\
\text { LILACS }\end{array}$ & $\begin{array}{l}\text { Qualitativo/ } \\
\text { Estudo de caso }\end{array}$ & $\begin{array}{l}\text { Interculturalidade e formação } \\
\text { acadêmica } \\
\text { A experiência universitária na } \\
\text { reconfiguração do Self, a partir } \\
\text { das dimensões analisadas no } \\
\text { desenvolvimento psicossocial. }\end{array}$ \\
\hline \multicolumn{5}{|c|}{ DESCRITOR: EDUCAÇÃO SUPERIOR E INDÍGENAS } \\
\hline 7. & $\begin{array}{l}\text { Cotas Universitárias no Brasil: } \\
\text { Análise de uma década de } \\
\text { produção científica }\end{array}$ & $\begin{array}{l}\text { 2017/Psicol. } \\
\text { esc. educ./ } \\
\text { LILACS }\end{array}$ & $\begin{array}{l}\text { Qualitativo/ } \\
\text { "Estado da arte" }\end{array}$ & $\begin{array}{l}\text { Ações afirmativas } \\
\text { Sistematização das publicações } \\
\text { sobre as Cotas em uma década no } \\
\text { Brasil. }\end{array}$ \\
\hline
\end{tabular}




\begin{tabular}{|c|c|c|c|c|}
\hline & Título & $\begin{array}{l}\text { Ano/ } \\
\text { Periódico/ } \\
\text { Base de }\end{array}$ & Tipo de Estudo & Reflexões/conclusões \\
\hline 8. & $\begin{array}{l}\text { A função social do acesso ao } \\
\text { ensino superior diante da sub- } \\
\text { representatividade dos povos } \\
\text { originários: uma análise acerca } \\
\text { da política pública de cotas (lei } \\
N^{o} 12.711 / 2012 \text { ) e da resistência } \\
\text { indígena no Brasil }\end{array}$ & $\begin{array}{c}\text { 2016/Barbarói/ } \\
\text { LILACS }\end{array}$ & $\begin{array}{l}\text { Qualitativo/ } \\
\text { Dedutivo,Histórico } \\
\text { documental }\end{array}$ & $\begin{array}{l}\text { Ações afirmativas } \\
\text { (Sub)Representatividade dos } \\
\text { povos originários e, a função social } \\
\text { das vagas no ensino superior. }\end{array}$ \\
\hline 9. & $\begin{array}{l}\text { A experiência do professor } \\
\text { orientador de estudante indigena } \\
\text { em enfermagem }\end{array}$ & $\begin{array}{l}\text { 2011/Acta } \\
\text { paul. enferm./ } \\
\text { LILACS }\end{array}$ & $\begin{array}{l}\text { Qualitativo/ } \\
\text { Relato de } \\
\text { experiência }\end{array}$ & $\begin{array}{l}\text { Interculturalidade e docentes } \\
\text { A comunicação terapêutica como } \\
\text { um instrumento do professor } \\
\text { orientador, diante da diversidade } \\
\text { cultural, em relação aos saberes do } \\
\text { cuidado. }\end{array}$ \\
\hline$D E S$ & RITOR: ESTUDANTE INDÍGE & 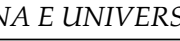 & $\mathrm{DADE}$ & \\
\hline 10. & $\begin{array}{l}\text { Disciplina de Saúde Indígena } \\
\text { na UnB: uma conquista do } \\
\text { Movimento Estudantil Indígena }\end{array}$ & $\begin{array}{c}\text { 2016/Tempus/ } \\
\text { LILACS }\end{array}$ & $\begin{array}{l}\text { Qualitativo/ } \\
\text { Estudo de caso }\end{array}$ & $\begin{array}{l}\text { Interculturalidade e formação } \\
\text { acadêmica } \\
\text { Formação acadêmica, por meio } \\
\text { do diálogo entre os saberes } \\
\text { tradicionais indígenase, os saberes } \\
\text { ocidentais. }\end{array}$ \\
\hline 11. & $\begin{array}{l}\text { Identidades em reinvenção: } \\
\text { o fortalecimento coletivo de } \\
\text { estudantes indígenas no meio } \\
\text { universitário. }\end{array}$ & $\begin{array}{l}\text { 2017/Rev. } \\
\text { polis psique./ } \\
\text { LILACS }\end{array}$ & $\begin{array}{c}\text { Qualitativo/ } \\
\text { Análise temática }\end{array}$ & $\begin{array}{l}\text { Ações afirmativas } \\
O \text { aumento do número de } \\
\text { estudantes indígenas e a } \\
\text { reinvenção identitária } \\
\text { fortalecimento de coletivos. }\end{array}$ \\
\hline
\end{tabular}

Fonte: Dados da pesquisa, 2020.

A análise dos estudos evidenciou o maior número de publicações no ano de 2017, concentrando 4 (quatro) (36,3\%) artigos. Entre os 11 artigos analisados, dez (dez) $(90,9 \%)$ foram publicados em periódicos diferentes, em maior número por revistas na temática de psicologia e educação. A abordagem qualitativa foi evidenciada em todos os estudos, porém com maior número (4 (quatro) $(36,6 \%))$ de relatos de experiência,

O contexto em que os estudos foram construídos foi agrupado em categorias temáticas: Interculturalidade e formação acadêmica, 5 (cinco) $(45,4 \%)$; Ações afirmativas, 5 (cinco) (45,4\%); e Interculturalidade e docentes, apenas 1 (um) $(9,0 \%)$;

A interculturalidade na educação emerge como uma proposta pedagógica que busca desenvolver relações de cooperação, respeito e aceitação, entre diferentes culturas e sujeitos, visando dessa forma preservar as identidades culturais e com o objetivo de propiciar a troca de experiências, e o enriquecimento mútuo, ratificando que a educação intercultural exige uma revisão crítica dos métodos e conteúdos do aprendizado para que sejam contemplados aspectos da vida multicultural (Vieira, 2001). Enquanto Fleury (2002), ressalta que a perspectiva intercultural implica uma compreensão complexa de educação, que busca para além das estratégias pedagógicas e 
mesmo das relações interpessoais imediatas entender e promover lenta e prolongadamente a formação de contextos relacionais e coletivos de elaboração de significados que orientam a vida das pessoas. Outrossim, Geertz (2001) e Barth (2011), defendem a cultura como um sistema simbólico que compõe os processos psíquicos dinamicamente reconstruído nas fronteiras entre os grupos, como mediador central aonde os partícipes compartilham, interpretam e reconfiguram sentidos e significados.

Do ingresso à universidade, os jovens vivenciam tensões impactantes na organização do seu percurso de vida, rupturas afetivas e culturais, como reflexos das relações que estabelecem no contexto universitário, que os levam a construir novas referências identitárias, habilidades e significados, processo caracterizado como transições (ZITTOUN, 2005). As transições inerentes ao quotidiano universitário são despertadas por experiências desafiadoras, prazerosas, mas também estressantes, que levam os estudantes a buscarem e construírem diversas estratégias de enfrentamento. Todavia, àqueles jovens em vulnerabilidade biopsicossocial ou com histórico de preconceito étnico-racial, a experiência universitária possibilita a emergência de novos posicionamentos identitários, devido à presença de outros significativos aqui entendidos como recursos simbólicos, que orientam a construção de novos conhecimentos, novas referências espaço-temporais, conflitos e confrontos, descobertas e despertares (RESSURREIÇÃO; SAMPAIO, 2017).

De acordo com Bruner (2001), pela perspectiva sociocultural da educação, o sujeito da aprendizagem é protagonista do seu processo de escolarização ao mesmo tempo em que é constituído pela cultura organizacional onde se insere. Ademais, as experiências educacionais também elaboram a trajetória de vida com importante impacto no desenvolvimento do sujeito. Sendo, que a educação é a busca constante de adequação de uma cultura às necessidades dos sujeitos e ao modo como estes significam os saberes socializados para ajustar-se às necessidades do seu grupo social. Desse modo, observa-se que a universidade promove aquisição e prevalência de elementos culturais, que facilitam as transições no desenvolvimento dos jovens nos processos de aprendizagem. A vivência universitária evidencia as diferenças culturais de cognição, principalmente naqueles jovens submetidos a um histórico de escolaridade menos favorável à apropriação rápida das ferramentas necessárias na educação superior (RESSURREIÇÃO; SAMPAIO, 2017).

E Zittoun (2012), propõe dois modelos para analisar a dinâmica biopsicossocial das transições inerentes à área da educação: um considera as rupturas sentidas como descontinuidades, que levam a transições na aprendizagem nos processos identitários e na construção de significados. O outro, analisa as transições como reconfigurações do prisma semiótico que articula Self, outros significativos, o objeto e o sentido do objeto numa situação social específica. 
Porém, a vivência de transição de vida e quotidiano frequentemente pode comprometer o processo de ensino e aprendizagem, gerar desestímulo e sofrimento mental, baixa qualidade de vida, e comprometimento da permanência universitária. Considerando a experiência prática e os resultados desta revisão, evidencia-se que apesar dos potentes desafios para a qualificação da educação intercultural, ainda são insipientes as discussões, reflexões e ações, nesta área. Com isso, revelando-se, a maior importância dada ao acesso do que à permanência dos povos indígenas no ensino superior.

A melhor oportunização de acesso, dos povos indígenas à universidade instituída pela Política de Ações Afirmativas (BRASIL, 2012) consistem em Políticas Públicas (e também privadas) voltadas à concretização do princípio constitucional da igualdade material e à neutralização dos efeitos da discriminação racial, de gênero, idade, cultural, religiosa, de origem nacional, pela constituição física e situação socioeconômica. Sendo impostas ou sugeridas pelo Estado, por seus entes vinculados e até mesmo por entidades privadas, elas visam a combater não somente as manifestações flagrantes de discriminação, mas também a discriminação cultural e estrutural, enraizada na sociedade. Sendo de natureza pedagógica e caráter de exemplaridade têm como meta, também, o fortalecimento de transformações culturais e sociais relevantes, motivando os atores sociais à utilidade e a necessidade de observância dos princípios do pluralismo e da diversidade nas mais diversas esferas do convívio humano (GOMES, 2001).

Apesar da Lei Cotas (BRASIL, 2012), contemplar ações afirmativas, no acesso à educação superior, os obstáculos à permanência universitária, ainda, emergem como impactante desafio. Observa-se a incipiência ora ausência de políticas estudantis biopsicossociais e pedagógicas, dentro das universidades, que propõem melhores construções curriculares, e/ou de acesso à redes de cuidados. Na amplitude de prioridades para alcance de metas e objetivos gerenciais e institucionais, não se observa importante foco, na qualidade da permanência dos povos indígenas. A estruturação curricular, o planejamento do processo de ensino e aprendizagem, e o acolhimento discente/docente, ainda repercutem no embate à uma experiência universitária adequada e emocionalmente positiva.

As necessidades do estudantes indígenas vão além do recurso financeiro, oportunizado por meio bolsas de permanência, moradia e alimentação, devem abranger outros fatores fundamentais que contemplem uma política de permanência (DOMENICO, 2018), a sensibilização e participação da comunidade universitária nas políticas de diversidade; o apoio à formação com cursos de leitura, escrita, informática, idiomas e monitorias de cursos específicos, e a valorização das trajetórias e identidades estudantis. Por meio destes, busca-se fortalecer o diálogo com a população excluída do ambiente acadêmico, tentando superar o preconceito e os processos de exclusão (DOMENICO, 2018). 
Há necessidade que a experiência/vivência universitária aconteça de forma impactante frente as transições esperadas, todavia, que sejam propulsoras, empoderantes, e culminem na potencialização da melhoria do processo de ensino e aprendizagem e na qualidade de vida dos estudantes.

\section{CONCLUSÃO}

A produção de conhecimento quanto a vivência universitária dos povos indígenas ainda é incipiente, diante da repercussão das políticas afirmativas, nas transformações educacionais, socioeconômicas e biopsicossociais para o indivíduo, família e/ou comunidades. Doravante, espera-se que esta revisão sensibilize e mobilize para o aumento das discussões e ações no âmbito da qualidade da permanência do estudante indígena na universidade entre todos os atores participantes desta experiência.

\section{REFERÊNCIAS}

ANGELIN, A. P.; ZOLTOWSKI, A. P. C.; TEIXEIRA, M. A. P. A construção do projeto de vida e carreira em estudantes indígenas: um estudo exploratório. Psicol. soc., 29: e161330, 2017.

BARTH, F. (2011). Os grupos étnicos e suas fronteiras. Em: P. Poutignat, P; \& J, Streiff-Fernart (Orgs.), Teorias da etnicidade (2a.ed., pp.185-227). São Paulo: Ed. Unesp.

BECKER, M. A.; NINO, C. G. R.; WEIGEL, V. Pesquisa na área Sateré-Mawé: a descoberta de talentos indígenas. Psicol. esc. educ; 13(1): 55-63, 2009.

BRASIL. Ministério da Justiça e Segurança Pública. Estudantes indígenas ganham as universidades. Disponível em: <https://www.justica.gov.br/news/estudantesindigenas-ganham-as-universidades $>$. Brasília (DF), 2018.

BRASIL. Ministério da Educação. Censo da educação superior. Notas Estatísticas 2017. Diretoria de Estatísticas Educacionais (DEED). Brasília (DF), 2017. Disponível em: <http://download.inep.gov.br/educacao_superior/censo_superior/ documentos/2018/censo_da_educacao_superior_2017notas_estatisticas2.pdf>

BRASIL. Lei de Cotas para o ensino público federal, de nível médio-técnico e, superior. Brasília, (DF), 2012. Disponível em:<http://www.planalto.gov.br/ ccivil_03/_ato20112014/2012/lei/112711.htm>.

BRUNER, J. A cultura da educação. Porto Alegre: Artes Médicas, 2001.

FLEURI, R. M. (Org.). Intercultura: estudos emergentes. Ijuí, RS: Unijuí, 2002.

GEERTZ, C. (2001). Nova luz sobre a antropologia. Rio de Janeiro: Zahar. 
GUARNIERI, F. V.; MELO-SILVA, L. L. Cotas Universitárias no Brasil: Análise de uma década de produção científica. Psicol. esc. educ., 1(2): 183-193, 2017.

GUIMARÃES, D. S. et al. Temporalidade e Corpo numa Proposta de Formação do Psicólogo para o Trabalho com Povos Indígenas. Psicol. ciênc. prof., 39(spe): 147-158, 2019.

HOEFEL, M. G. L.; SEVERO, D. O. Disciplina de Saúde Indígena na UnB: uma conquista do Movimento Estudantil Indígena. Tempus (Brasília), 10(4): 229-234, 2016.

MAYORGA, C.; SOUZA, L. M. Ação afirmativa na universidade: a permanência em foco. Revista Psicologia Política, v. 12, n. 24, p. 263-281, 2012.

RESSUREIÇÃO, S. B.; SAMPAIO, S. M. R. Transições e reconfigurações do self de jovens indígenas na experiência universitária. Psicol. esc. educ, 21(3): 495-504, 2017.

SAMPAIO, S.M.R. Educação superior como espaço privilegiado para orientação acadêmica. Em: R.S.L, Guzzo; \& C.M, Marinho-Araújo(Orgs.), Psicologia escolar: identificando e superando barreiras (pp.215-228). São Paulo: Alínea, 2011.

SHADICK, R.; DAGIRMANJIAN, F. B.; BARBOT, B. Suicide Risk Among College Student. The Intersection of Sexual Orientation and Race. Crisis, 36(6): 416-23, 2015.

TERRA, R. B. M. R. B.; DAVID, T. D. A função social do acesso ao ensino superior diante da sub-representatividade dos povos originários: uma análise acerca da política pública de cotas (lei No 12.711/2012) e da resistência indígena no Brasil. Barbarói; (47, n.esp): 107-124, 2016.

UHNG HUR, D.; COUTO, M. L. B. S.; NASCIMENTO, J. S. Estudantes indígenas na Universidade: uma sessão de grupo operativo. Pepsic, 15(2): 99-119, 2018.

VEGNERS, E. C.; Joaquim Benedito Barbosa Gomes - Ação Afirmativa \& Princípio Constitucional da Igualdade: o direito como instrumento de transformação social. A experiência dos EUA. Rio de Janeiro: Renovar, 2001, p. 6-7.

VELOSA, E. M. O.; MELLA, E. R. Experiências de estudantes mapuches em formação inicial docente no contexto de diversidade. Psicol. esc. educ., 21(3): 621-628, 2017.

VERA, I.; AVERSI-FERREIRA, T. A.; LUCCHESE, R. A experiência do professor orientador de estudante indígena em enfermagem. Acta paul. Enferm., 24(2): 289-293, 2011.

VIANA, I.; MAHEIRIE, K. Identidades em reinvenção: o fortalecimento coletivo de estudantes indígenas no meio universitário. Rev. polis psique., 7(3): 224-249, 2017.

VIEIRA, R. S. Educação intercultural: uma proposta de ação no mundo multicultural. In FLEURI, R. M. (Org.). Intercultura: estudos emergentes. Florianópolis: MOVER; Ijuí: Ed. Unijuí, 2001, p. 117-127. 
VITALES, M.P; GRUBITS, S. Psicologia e povos indígenas: um estudo preliminar do “estado da arte". Revista Psicologia e Saúde, 1(1), 15-30, 2009.

WHITTEMORE, R.; KNAFL, K. The integrative review: updated methodology. J Adv Nurs, 2005. Disponível em: < https:/ / pubmed.ncbi.nlm.nih.gov/16268861/>.

ZITTOUN, T. On the emergence of the subject. Psychological and Behavioral Science, 46(3), 256-273, 2012.

ZITTOUN, T. Transitions: symbolic resources in development. Charlotte, NC: Information Age Publishing., 2005. 